\title{
WHAT IF MICROBES COULD LIVE IN EXTREME ENVIRONMENTS BEYOND EARTH?
}

\author{
DR JAY NADEAU, BASED AT PORTLAND STATE UNIVERSITY, USA, \\ IS ON A QUEST TO FIND LIFE IN EXTREME ENVIRONMENTS. HER \\ FINDINGS COULD HELP INFORM THE SEARCH FOR BUGS IN SPACE
}

\section{TALK LIKE A MICROBIOLOGIST}

MICROBES - tiny living things that are found all around us and are too small to be seen by the naked eye

MICROBIOLOGY - the study of all living organisms that are too small to be visible with the naked eye

MOTILITY - the ability of an organism to move independently, using metabolic energy

ORGANELLES - subcellular structures, usually enclosed by membranes, that have one or more specific jobs to perform in the cell
PROKARYOTES - cellular organisms that lack an envelope-enclosed nucleus and membrane-enclosed organelles. Bacteria and archaea are two domains of prokaryotic life

\section{EUKARYOTES (EUKARYA) - the third} domain of life, consisting of all organisms with their DNA enclosed in nuclei. This domain includes all animals, plants and fungi

NUCLEIC ACIDS - the biopolymers, or large biomolecules, essential to encoding genetic information in all known forms of life (the overall name for DNA and RNA)
ARCHAEA - any of a group of singlecelled prokaryotic organisms that have distinct molecular characteristics separating them from bacteria

ABIOTIC - relating to things in the environment that are not living

ENTROPY - a thermodynamic function that describes the randomness and disorder of molecules based on the number of different arrangements available to them in a given system or reaction
Despite the efforts of scientists and researchers, we only know of one place in the entire Universe where life has evolved - Earth. The number of things that had to happen for life to evolve - and often in a particular order - on our planet seems so unimaginably massive, that we might all reasonably be considered walking miracles. But is this actually true? Is the origin of life rare - or incredibly common? We can only start to answer questions like these by looking for life elsewhere.

We can imagine that across the entire Universe, even if life is extremely rare, the immense spaces mean that it must be inevitable that life arose somewhere. But searching the entire Universe is very difficult. The best we can do right now is build specialised telescopes to look at faraway stars for orbiting planets and signs of oxygen in their atmospheres. If there are animals, plants, or bacteria living on those planets, we have no hope of getting to see them in our lifetimes.
To actually see extraterrestrial life, we need to go to places where we can land and deploy robotic instruments. So far, this has only been Mars, where no life has been found, but lately scientists have been increasingly interested in other parts of the solar system: Venus and the moons of the giant planets such as Jupiter and Saturn. The question is, how can we look for life in these places, and what kind of life can we expect?

Until recently, we thought that life in such places was impossible. Even on Earth, there are places that were believed to be too cold, too hot, or too dry for life, until microbiologists found otherwise. By looking for Earth sites that are as similar as possible to sites on other planets, scientists hope to go to these planets better prepared to find microbes. These sites are called 'extraterrestrial analogue' sites.

Dr Jay Nadeau, a physicist based at Portland State University in the US, is on a quest to find evidence of life in analogue sites. Evidence of life in incredible places appears all the time, at extremely high or low temperatures, high pressures and sometimes with no apparent food sources. Tardigrades are a brilliant example of this - these microscopic animals have shown they can survive for years without water, in sub-zero temperatures and in space! It is not an exaggeration to say that tardigrades are the toughest animals on Earth.

WHICH EXTREME ENVIRONMENTS HAS JAY SEARCHED FOR BUGS?

Jay and her team have investigated sites in some of the most extreme environments on Earth, including sea ice in Greenland, pools in Death Valley and Ash Meadows in the California desert, mineral springs in The Cedars in the California mountains, and permafrost in Alaska. In all these places, the researchers have found a wide variety of microorganisms with incredible diversity. This is important because it shows that it is not just 


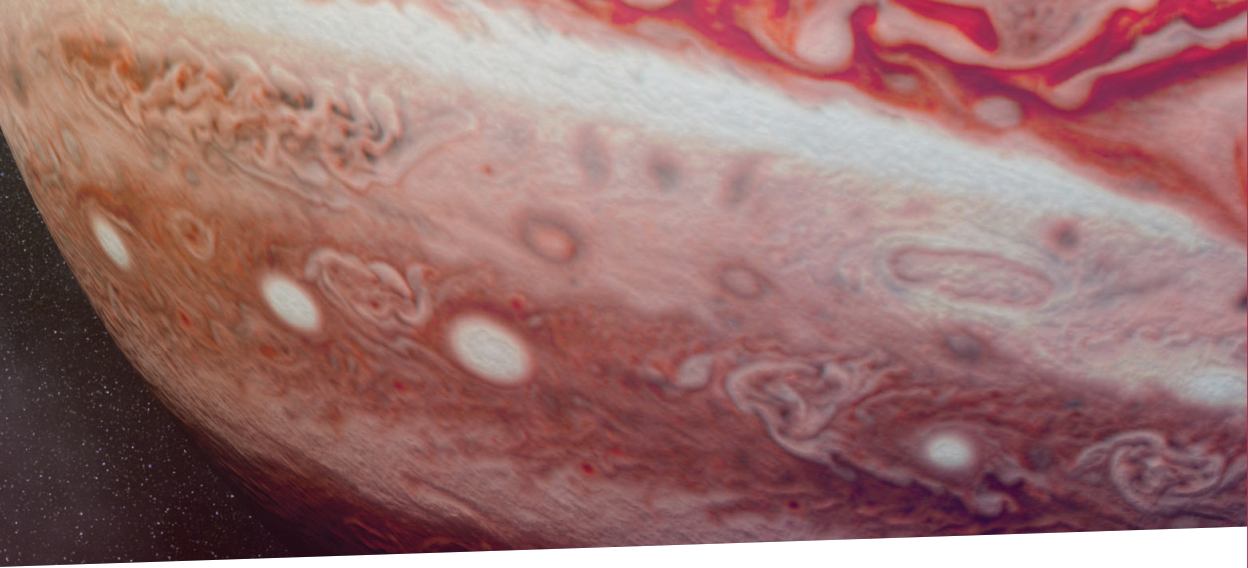

one form - or type - of life that can thrive in these environments. While some of the microorganisms that have been discovered are eukaryotes, others are prokaryotes.

\section{WHAT EXCITING DISCOVERIES HAS JAY MADE ABOUT MICROORGANISMS?}

One of the most remarkable aspects of these microorganisms is their motility, that is, the ability of organisms to be able to move by themselves. Indeed, from Jay's research it appears that there is always something moving. "When we first went to Greenland, we had no idea if we were going to see anything at all, but then, right away, something swam across the screen. The fraction of cells that swim and the speed at which they swim are highly dependent upon factors such as nutrients and temperature," explains Jay. "We have seen organisms that swim their fastest at $4^{\circ} \mathrm{C}$ - the same temperature as your refrigerator - and start dying when the heat reaches what we call room temperature. On the other hand, some hot spring organisms can't swim at all until they reach $85^{\circ} \mathrm{C}$ and are happiest just below boiling."

\section{WHY IS MOTILITY IMPORTANT IN JAY'S RESEARCH?}

Somewhat remarkably, scientists do not have a reductionist definition of what it means to be 'alive' - there is no mathematical definition or chemical formula that determines whether something is living. The only way to determine whether something is alive is by observing life-like behaviours, such as the ability to reproduce or evolve through natural selection. However, these behaviours can be very difficult to measure. Motility, on the other hand, is a much easier behaviour to measure. Technological advances have helped enormously, as the development of digital video microscopy and other types of microscopy have helped scientists peer at things much more closely, and record and analyse what they see, making observing the motility of microorganisms possible. Advances in computer technology have been just as important as developments in optics because recording motion involves generating a lot of data very quickly and often complex computational analysis.

\section{IS JAY USING MICROSCOPES IN HER RESEARCH?}

Yes! She and her team of collaborators at Caltech's Jet Propulsion Laboratory have developed a holographic microscope named SHAMU, an acronym that stands for Submersible Holographic Astrobiology Microscope with Ultraresolution. "SHAMU is a holographic microscope specifically designed to look for the smallest microorganisms, bacteria and archaea, in liquid environments. Its key feature is its high resolution, where it is able to image individual bacteria down to 700 $\mathrm{nm}$ in size, and its ability to be used outside in the field," says Jay. "Many other holographic microscopes exist but SHAMU uses a type of $3 D$ microscopy, where a single image encodes for the information in the entire sample depth. Holographic microscopes tend to be delicate and require careful laboratory use in rooms without noise or vibration. Field instruments usually have lower resolution so they cannot see bacteria. SHAMU was made with these particular applications in mind so that we could see bacteria and archaea in their native environments."

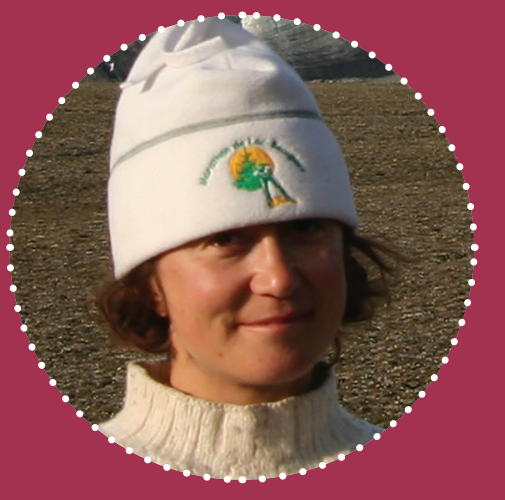

DR JAY NADEAU

Associate Professor, Department of

Physics, Portland State University, USA

..........

FIELD OF RESEARCH

Physics, Microbiology and Space

•........

\section{RESEARCH PROJECT}

Jay is looking for signs of life in some of the most extreme environments on Earth. Her studies will help inform the search for life in space and possibly revolutionise our understanding of the conditions in which life can thrive.

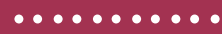

FUNDERS

Moore Foundation, NASA, JPL National Science Foundation

HOW IS JAY SEARCHING FOR MICROORGANISMS IN SPACE?

Unfortunately, to determine whether there is life in space it is not enough to be looking in the right places - you also need the right tools, methods and approaches. If something is observed moving (a sure sign that it is alive), then it is important to actually know what this living thing is! Microscopy is essential in observing life, but a variety of chemistry instruments are also important, as they will help Jay and the team understand what components make up alien biochemistry.

"The search for biochemistry starts with building blocks, such as lipids that make up membranes, amino acids, which make up proteins, and nucleic acids which encode genetic information. We know, however, that simple building blocks can form abiotically, and have even been found in interstellar space and on asteroids," explains Jay. "Chemical studies will therefore look for more complex assemblies of building blocks, such as proteins, and attempt to classify them. Some approaches will look at the overall complexity of a sample, to find evidence of local reductions in entropy that are characteristic of life." 


\section{SEARCHING FOR LIFE IN SPACE}

It is fair to say that if evidence of life can be found in space it would be one of the most remarkable discoveries that has ever occurred. In many ways, it seems staggeringly simplistic to think that across the infinity of the Universe, life only managed to find a way to exist on Earth. On the other hand, we do not know how specific the conditions and requirements for life are, or how likely each step is in the complex chain of events that leads from molecules to cells. To date, we have only looked at one place outside Earth - the planet Mars - and even that has not been fully explored. We genuinely have no idea of how rare or common life might be.

Jay's research into finding life in extreme environments has challenged many of the preconceptions we have about the conditions in which life can thrive, which opens up more possibilities in terms of the environments in which we may find evidence of life. Life on Earth is relatively fragile. Eukaryotes - from the smallest algae to large animals and plants - require oxygen, and there is a narrow band of temperatures and water availability where complex life can live. However, Jay's research is providing possible means of discovering life beyond Earth by altering our concepts of just how fragile life on Earth is.

\section{LIFE ON OTHER PLANETS}

Although current scientific knowledge shows us that complex life is impossible without oxygen, there are other forms of life - particularly bacteria and archaea - that can use chemicals in place of oxygen, including solid materials like iron! "Bacteria can withstand extremes of temperature, dryness, radiation, toxins, pressure and acceleration. They can be frozen for thousands of years and then revived. Prokaryotes have also been around on Earth for at least 4 billion years; eukaryotes did not arise until 1 to 1.5 billion years later. What this suggests is that most life elsewhere may be microbial," says Jay. "There could be entire planets, in our solar system and elsewhere, that are entirely dominated by bacteria-like organisms. If we want to find extraterrestrial life, we need to be able to see these organisms."

\section{LOOKING FOR BUGS IN SPACE}

Just think about what finding life elsewhere would do to our understanding! Many scientists like Jay are aware of the remarkable conditions in which life on Earth can be found, and if their attempts to find life in space are successful, it would perhaps be less unbelievable to them (though no less incredible) than it would to you and me. It would be front-page news around the world, it would raise so many philosophical questions, it would challenge many of the things that people hold true. It would also have exciting scientific ramifications - is life abundant in the Universe? Does all of it look more or less similar?

"We don't know if water-based life would converge to using similar sets of building blocks as those found on Earth, such as amino acids and nucleobases," explains Jay. "Finding life elsewhere would fundamentally change our understanding of what life is, how it originates, and what circumstances are necessary for it to persist and evolve. Would Martian bacteria look just like E. coli - or completely different?"

\section{EUROPA}

Understandably, any scientific investigations into life that require sending robots to land have to take place within our own solar system. Even that is rather large - it measures 287.46 billion $\mathrm{km}$ across. Within that area, some scientists think that Jupiter's moon, Europa, is most likely to harbour life. This stems from the Galileo mission which suggested the presence of a liquid water ocean underneath a layer of ice (and our understanding that life requires liquid water). We also know that minerals such as phosphorous - which are derived from rocks are required, so a rocky core with a liquid water ocean contains all of the known requirements for life 'as we know it'.

Recently, scientists have expanded their search, however. "The Cassini mission discovered a liquid water ocean on Saturn's moon Enceladus in 2009. Several more sub-surface oceans have since been discovered on the moons Titan, Ganymede, and Callisto, and even on Pluto," says Jay. "These bodies, now collectively known as the 'Ocean Worlds', are all areas of great interest in the search for life. The Triton, Ceres and Dione moons are also candidate Ocean Worlds."

\section{HOW TO BECOME A PHYSICIST}

- The American Physical Society is a non-profit membership organisation working to advance the knowledge of physics. Have a read around the site to see what is happening in the field. https://www.aps.org

- Maths is of major importance to any budding physicist, as well as any physics classes you can take. Physics relates to many areas of science, so studying the fundamentals of biology and chemistry alongside it could also be beneficial.

- Salary.com claims that that average national salary in the US for a physicist is between $\$ 86,864$ and $\$ 127,552$. However, Jay is keen to explain that industry salaries are very different from academic salaries, and within academia, there are high- and low-paid positions.

\section{JAY'S TOP TIPS}

01 Take as many maths classes as you can, as soon as possible. Maths is useful for all sciences and any area you decide to go into will be easier to understand and get to grips with if you are well-versed in mathematical principles.

02 It's never too early to start thinking about where you want to go to college and what kind of research you might want to do. Each school has its own particular strengths and areas of research opportunity, so start thinking about this sooner rather than later! 


\section{HOW DID JAY BECOME}

\section{A PHYSICIST?}

WHO OR WHAT INSPIRED YOU TO STUDY PHYSICS?

I have loved Isaac Asimov's books ever since I was a kid, so I knew I wanted to study physics or chemistry. I had some terrific physics professors in college who really inspired me to pursue theoretical physics for my doctorate.

\section{HOW DOES A PHYSICIST END UP}

WORKING IN MICROBIOLOGY AND SPACE SCIENCE?

That's the funny thing about astrobiology it's not something you can study in school, really, so the people who work in the field come from a wide variety of backgrounds. All kinds of skills are needed to send a mission to another planet. First, you have the basic engineering, then there is the building and design of science instruments, then there is the design of scientific experiments which use these instruments, and finally the analysis of the data. Computer codes are also needed to control instruments and experiments, and figure out experiments on Earth that come as close as possible to what you want in space. There is truly something for everyone.

WHAT DO YOU LOVE ABOUT THE WORK YOU DO?

The best part is getting to travel to exotic locations that I would never have had the opportunity to see otherwise. There is nothing I love more than the midnight Sun.

YOU ARE THE FOUNDER AND EDITOR-IN-CHIEF OF BITINGDUCK PRESS, AN INDEPENDENT PUBLISHER THAT SPECIALISES
IN FICTION FOR AND ABOUT SCIENTISTS. DID YOU WANT TO BE A WRITER WHEN YOU WERE GROWING UP?

I sure did! I am a great fan of both fiction and narrative nonfiction, especially when nerdy characters are involved!

HOW DID YOU COME UP WITH THE NAME BITINGDUCK PRESS AND WHY IS THE FOCUS ON FICTION FOR AND ABOUT SCIENTISTS?

I had pet ducks and I can assure you - they do bite! I wanted to publish books that I wanted to read but couldn't find in bookstores. There are a lot of stereotypes about scientists, usually where they are either too good or too evil and I hope to redress this with the stories we publish.
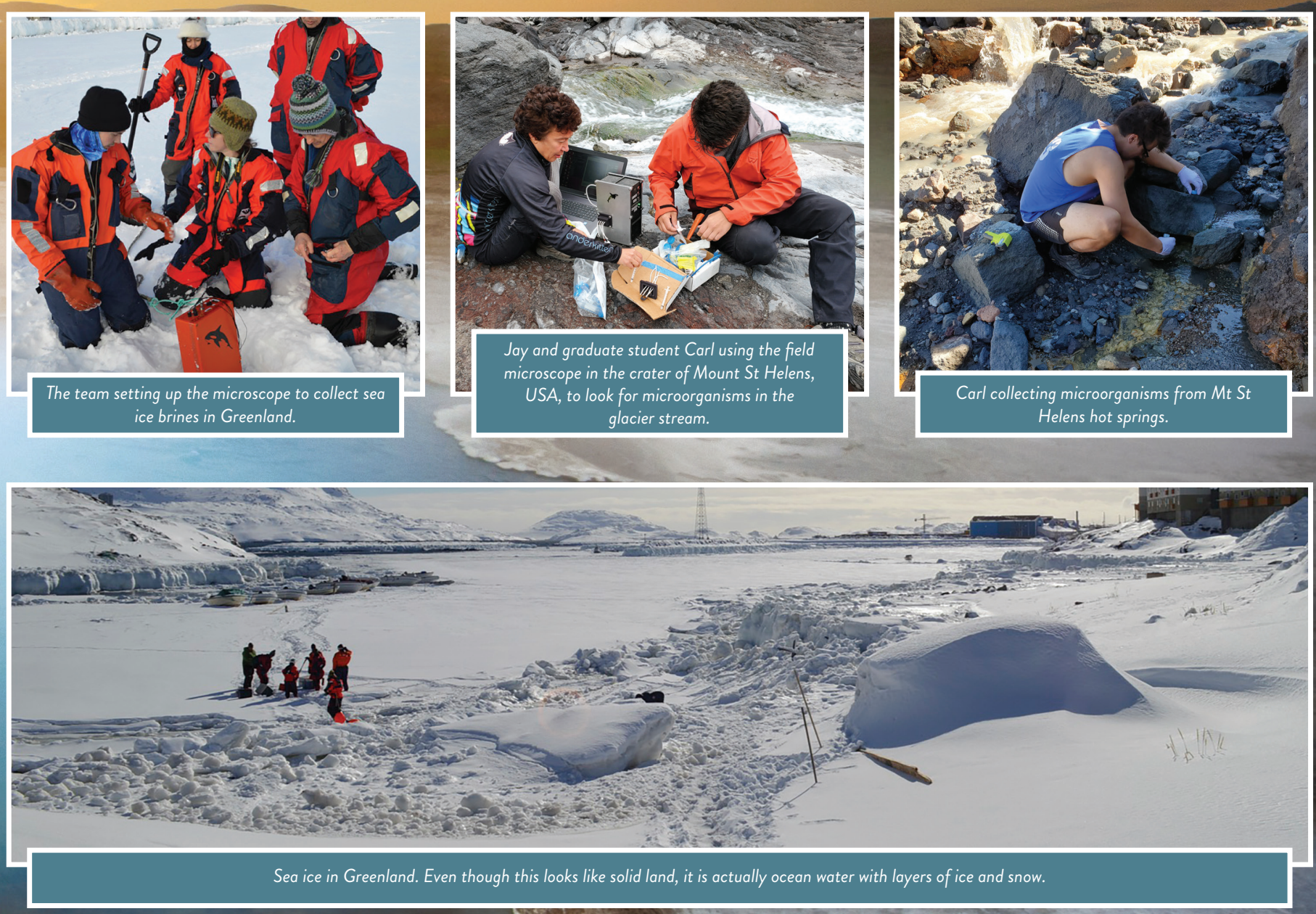